\title{
Richard Bright and His Neurological Studies
}

\author{
J.M.S. Pearce \\ Emeritus Consultant Neurologist, Department of Neurology, Hull Royal Infirmary, Hull, UK
}

\section{Key Words}

Richard Bright • Epilepsy • Cortical epileptogenesis ·

Neurological contributions

\begin{abstract}
Richard Bright was one of the famous triumvirate of Guy's Hospital physicians in the Victorian era. Remembered for his account of glomerulonephritis (Bright's disease) he also made many important and original contributions to medicine and neurology. These included his work on cortical epileptogenesis, descriptions of simple partial (Jacksonian) seizures, infantile convulsions, and a variety of nervous diseases. Most notable were his reports of neurological studies including papers on traumatic tetanus, syringomyelia, arteries of the brain, contractures of spinal origin, tumours of the base of the brain, and narcolepsy. His career and these contributions are outlined.

Copyright $\odot 2009$ S. Karger AG, Basel
\end{abstract}

Richard Bright, MD, Edinburgh, FRCP, FRS, at Guy's Hospital laid the foundation for those discoveries in glomerulonephritis which culminated in the eponym Bright's disease ${ }^{1}$, described in his two volume text (18271831) [1].

Guy's Hospital boasted many great and remembered physicians. Richard Bright (1789-1858), Thomas Addison (1793-1860), and Thomas Hodgkin (1798-1866) had their names and clinical discoveries perpetuated in familiar eponyms. They were contemporaries for 12 years from 1825 to 1837 , and became known as 'the three great men of Guy's'. In their wake, less famed, but of comparable stature, was Sir Samuel Wilks [2]. All four physicians excelled in general medical illnesses, but it is sometimes overlooked that Bright and Wilks (like Osler) also concerned themselves with diseases of the nervous system. This paper recalls Bright's contributions to the understanding of epilepsy and briefly portrays the man and his legacy.

\section{Cortical Genesis of Epilepsy}

The existence of cortical epileptogenesis was postulated (vide infra) by Richard Bright in 1831 and 1836, and was later highlighted by Robert Bentley Todd in his 1849 account of post-epileptic hemiplegia [3]. It was rediscovered independently by Samuel Wilks in 1866 [4]. When Bright began clinical practice, the prevailing idea was that epilepsy was essentially a rapidly reversible disorder of consciousness whether or not attended by tonic, clonic, psychomotor, or other features. Its prime source was located in the medulla. After primitive notions of divine,

Bright observed the connection of pathological changes in the kidney 'and the secretion of albuminous urine, more or less coagulable on the application of heat' in a dropsical patient. Between 1825 and 1827, he saw 23 cases that showed albuminuria; over half died, and all showed disease in the kidneys. These and other findings were published in 1827 [1]. This famous book first described Bright's disease, and started his rise to fame as the father of Nephrology.

\section{KARGER \\ Fax +41613061234 E-Mail karger@karger.ch} www.karger.com
(C) 2009 S. Karger AG, Base 0014-3022/09/0614-0250\$26.00/0

Accessible online at: www.karger.com/ene
J.M.S. Pearce

304 Beverley Road

Anlaby, East Yorks HU10 7BG (UK) 
demonic and mystical causes had abated, it was thought of as a disease sui generis, without discernible cause.

When an underlying cause was suspected or proven, attacks were labelled epileptiform, i.e. what we would call symptomatic epilepsy.

As a result of many minute bedside observations, Bright corrected many of the erroneous notions of his day and distinguished many patterns of epilepsy [5], some 30 years before Herpin [6,7] and Jackson's [8] invaluable studies.

Bright's (1831) 'Diseases of the brain and nervous system' (Vol. 2) [9] contains neuropathology details of more than 200 patients and his own beautiful illustrations in 25 elegant coloured plates. It clearly portrays what we now call absences and temporal or fronto-temporal complex partial seizures:

'The character of the fit itself varies as much as the premonitory symptoms often, it is simply a momentary absence of mind, the eye is fixed as in thought, yet gazing vacantly, no convulsion, no sound, the occupations of the hand ceases, while the mind for a moment is annihilated; the cloud passes off, the intellect returns, and often, unconscious that its operation has been suspended, the patient resumes the occupation in which he was engaged. At other times, this loss of mind is connected with a slight appearance of convulsive or involuntary action.'

\section{Simple Partial ('Jacksonian') Seizures}

His account of cases CCLI and CCLII closely resemble simple partial seizures without loss of consciousness. Of interest, is Bright's association of affection of speech (though few details are given) with the posterior portion of the left hemisphere, which long predates Bouilaud's frontal, and Broca's left fronto-temporal localisations ('we speak with the left hemisphere'). Although he does not clearly apportion the relation of arm and leg function to posterior and anterior regions of the hemisphere, his term the posterior portion of the hemisphere corresponds to post-Rolandic structures and thalamo-cortical projections:

'I have pretty well satisfied myself by an extensive induction of facts: and the circumstance of the right hand having suffered more than the leg, and the speech having been affected, directed my views to the posterior, rather than the anterior portion of the left hemisphere.'

\section{Infantile Convulsions or Epilepsy?}

In Bright's time, infantile convulsions were regarded as symptomatic of some systemic irritability often accompanied by fever, the cause being 'most of the [infec- tious] diseases of infancy' [10], as distinct from epilepsy which was frequently of unknown cause. Bright however believed that infantile convulsions and epilepsy were the same disorder.

\section{Aetiology and Nature of the Epileptic Seizure}

Bright commented at length about the aetiology of epilepsy, which was generally regarded as originating in the medulla:

'I should say that the organic causes of epilepsy, connected immediately with the brain, are more frequently such as affect its surface, than such as are deep seated within its substance. Thus we find that morbid growth, taking place in the skull, ... is often associated with epilepsy. Slow changes, producing a thickened condition of the membranes, will not unfrequently be found attendant on epileptic attacks. Tumours pressing on the surface, or amalgamated with the cineritious ${ }^{2}$ substance, will also be found in cases of epilepsy: ... It is an idea entertained by Dr. Foville, that the cineritious is the more active part of the brain generally, with regard to all its functions; and that the medullary part is more particularly employed in the conveyance of motions and sensation, or whatever else may be acted upon or produced in the cineritious part. And ... we might expect that lesions in the cineritious substance would produce disordered action in that part; and that such action might be transferred to the distant parts of the body, producing disordered and involuntary motions.'

There seems little doubt that Bright wrote the original account and laid the basis for Todd and Wilks in implicating the cortex in the genesis of epilepsy and for the further elucidation of Herpin and Hughlings Jackson. Nearly 20 years after Bright, Robert Bentley Todd published Diseases of the Brain and Other Affections of the Nervous System (1854) and edited the 6,000-page 'Cyclopaedia of Anatomy and Physiology' in 5 volumes (18351859) [11] celebrated for its scope and scientific originality. Todd distinguished 'three kinds of convulsions' - the jactitating or choreic, tetanic or tonic, and clonic or epileptiform, but he is best known for his account of postepileptic paralysis (epileptic hemiplegia) clearly implicating a cortical genesis of epilepsy, described in the Lumleian lecture:

'A paralytic state remains sometimes after the epileptic convulsion. This is more particularly the case when the convulsion has affected only one side or one limb: that limb or limbs will remain paralytic for some hours, or even days, after the cessation of the paroxysm, but it will ultimately perfectly recover.'

\footnotetext{
2 Literally: ashen. Used of the 'grey-matter' of the brain and spinal cord.
} 


\section{Todd in 1849 commented:}

'The part of the encephalon primarily disturbed, is the hemispheric lobes: if the disturbance did not go beyond a certain point, the phenomena are limited to loss of consciousness and impaired intellectual action, with more or less of sopor. But if the disturbance be considerable, then the tuberculae quadrigemina and mesocephale become involved, and epileptic convulsions are produced. If the disturbance of this centre be very great, the medulla oblongata and the medulla spinalis become much excited and the convulsions are complicated with a good deal of the tetanic character' [12].

This indicates Todd's anticipation of a cortical epilepsy with secondary generalisation.

In Bright's time, epilepsy as a disease in which no cause was apparent was distinguished from epileptiform attacks, which were the outward manifestations of a demonstrable cortical lesion. However, Wilks had said:

'We cannot conclude that the fons et origio mali is in the cineritious substance of the brain. I believe that in this region a commotion occurs which would perhaps be analogous to a palpitation affecting the heart, and that this irritates the ganglia below, which form the summit of the motor tracts' [13].

Thus his use of 'epileptiform' was conventional but arbitrary and gradually was later abandoned in informed circles.

\section{Bright the Physician}

Richard Bright [14] (fig. 1) was born on September 28, 1789. His father Richard Bright was a prosperous merchant and banker of Ham Green near Avonmouth, who had a town house, 29 Queen Square, Bristol. After schooling in Bristol and Exeter, in 1808 he went to Edinburgh. Richard Bright's enrolment appears in the Faculty Register for $1808 / 10$. He bought tickets to attend lectures by Professor Dugald Stewart on political economy, by Professor John Playfair on natural philosophy, and on mathematics given by Sir John Leslie. He entered the Medical Faculty in the autumn of 1809. But he interrupted his studies with a Natural History expedition to Iceland with Sir George Mackenzie and wrote biological sections in Sir George's Travels in Iceland. On his return, he resumed his studies at Guy's Hospital and was a pupil of Sir Astley Paston Cooper. He returned to Edinburgh ${ }^{3}$ to graduate $\mathrm{MD}$, writing a thesis, de Erysipelate Contagioso. He came back to Guy's for further training.

\footnotetext{
3 For details of Bright's studies in Edinburgh, see Berry D: Richard Bright (1789-1858): student days in Edinburgh. Proc R Coll Physicians Edinb $1994 ; 24: 383-396$
}

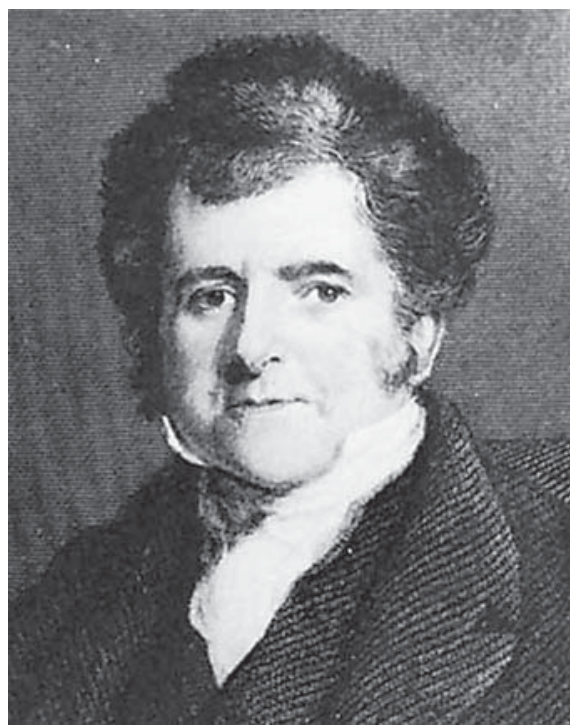

Fig. 1. Richard Bright, MD, FRS. Engraving by H. Cook after a portrait by Frederick Richard Say.

He was elected assistant physician to the London Fever Hospital. After further travels into Europe, in 1820 he set up practice in 14, Bloomsbury Square, and was appointed assistant physician, and in 1824 full physician to Guy's Hospital. There he was astonishingly busy with active roles in teaching, clinical duties and research. He was elected FRS in 1821. His prolific artwork was highly regarded; a collection with drawings (including original drawings for his Reports) and case notes (1822-39, MS 974/1-106) resides at The Royal College of Physicians.

Bright's Reports of Medical Cases, selected with a view to illustrate the Symptoms and Cure of Diseases by a reference to Morbid Anatomy appeared in two volumes, quarto, 1827-1831. Munk remarked that upon each and all of the varied subjects treated in this work, he showed the most sagacious observation, untiring industry, and wonderful powers of investigating truth. Here he related that symptoms of kidney disease and deduced the causes and sequelae. 'It is curious and instructive to us all,' said his friend, Sir Charles Locock,

'to note how closely and entirely he worked out his investigations; how absorbed he was solely in making out their true value, ... and ending in axioms which have been universally recognised, because felt to be genuine and true' [15].

He employed his remarkable powers of observation to describe acute yellow atrophy of the liver, pigmentation of the brain, condensation of the lung in whooping cough, unilateral convulsion without loss of consciousness in lo- 
cal cerebral diseases, and the cardiac murmur in chorea [16]. His neurological studies include papers on traumatic tetanus [17], syringomyelia [18], arteries of the brain [19], contractures of spinal origin [20], and tumours of the base of the brain [21]. Narcolepsy is often suggested as the explanation for his case of: 'Mrs W aged 67 has been for 30 or 40 years, subject to a "most remarkable drowsiness" [22]. It is also alleged that Bright regarded herpes zoster as spread of (varicella zoster) a virus along the nerves [23].

Much of his career and publications were listed in The Medical Times and Gazette [24]. Richard Bright was admitted FRCP on June 25, 1832; he was Goulstonian (1833) then Lumleian (1837) lecturer to the Royal College of Physicians. He was appointed Physician Extraordinary to Queen Victoria.

He died at his house in Savile Row on December 16, 1858, after a 4-day illness. He had received patients and was out in his carriage on the previous Saturday. It is rare to have a contemporary account of the final illness of such a distinguished physician:

'Saturday, December 11, when, about midnight, he was seized with haemorrhage from the bowels, with great prostration of strength and difficulty of breathing, assuming the form of angina pectoris. He was attended by Dr. Babington and Dr. Latham, and Dr. Watson was subsequently called in consultation. From these three physicians, in conjunction with his friend and neighbour, Mr. H.C. Johnson, he received the most unremitting attention, until the night of Wednesday, December 15, when he was visited about 12 o'clock by Dr. Babington, whom he recognised, and about half past 12 o'clock by Sir Charles Locock, in whose presence he breathed his last' [24].

He was buried at All Souls, Kensal Green. A London Blue Plaque marks his home at 11 Savile Row (fig. 2). In Wren's late 17th century church of James's, Piccadilly, is a simple mural monument, bearing an inscription (fig. 3).

His friend and colleague, the influential Dr. George Hilaro Barlow (1806-1866), wrote:

Dr. Bright 'was of a remarkably even temper and cheerful disposition; most considerate towards the failings of others, but severe in the discipline of his own mind. He was sincerely religious, both in doctrine and in practice, and of so pure a mind that he was never heard to utter a sentiment or to relate an anecdote that was not fit to be heard by the merest child or the most refined female. He was an affectionate husband and an excellent father, not only taking the most lively interest in the welfare of his children and in their pursuits, but never so happy as when he had them around him. He was perhaps better known abroad throughout the civilized world than any other British physician of modern times, and in his own country was pre-eminently sought for by his professional brethren in cases of difficult diagnosis. His eminent position was fairly, though tardily, won by his thoroughly practical writings and great discoveries; and was sustained by his amiable manners, by his uniformly honourable conduct to his profession-

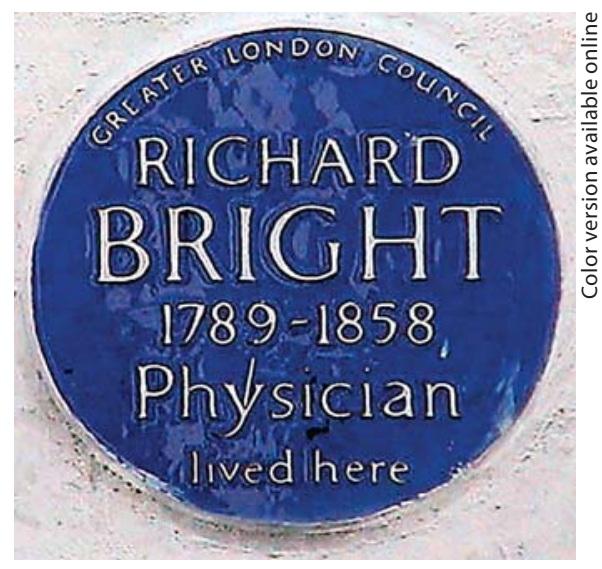

Fig. 2. Blue plaque at Bright's home,11 Savile Row, London.

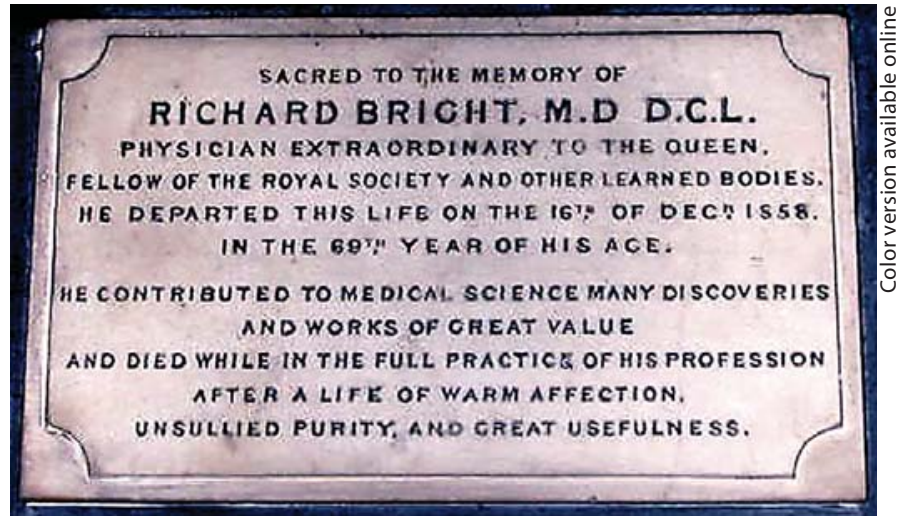

Fig. 3. Memorial in (Christopher Wren's) Church of James's, Piccadilly.

al brethren, his sound judgement and knowledge of disease, and by the pains which he took in investigating the most minute particulars of every case which was brought before him' $[25,26]$.

Richard Bright [27] was twice married, first to Martha, youngest daughter of William Babington, MD, FRS, ${ }^{4}$ and secondly to the youngest daughter of Benjamin Follett, of Topsham, Devon. He left a widow, two daughters, and three sons. His drawings and case notes 1822-1839 he gave to The Royal College of Physicians; the College possesses a bust presented by his widow, and a portrait painted at the expense of the College, 'in honour of his memory'. The Richard Bright Renal Unit at Southmead Hospital, Bristol, is a lasting tribute to this fine physician.

4 Sometime physician to Guy's Hospital. 


\section{References}

1 Bright R: Reports of Medical Cases Selected with a View of Illustrating the Symptoms and Cure of Diseases by a Reference to Morbid Anatomy. Part 1. London, Longman, Rees, Orme, Brown \& Green, 1827.

2 Pearce JMS: Sir Samuel Wilks (1824-1911): 'the most philosophical of English physicians.' Eur Neurol 2008 (in press).

3 Todd RB: Lumleian lectures (1849-50) on the Pathology and Treatment of Convulsive Disease. Royal College of Physicians, London.

4 Eadie MJ: Cortical epileptogenesis - Hughlings Jackson and his predecessors Epilepsia 2007;48:2010-2015.

5 Pearce JMS: Richard Bright and epilepsy. J Neurol Neurosurg Psychiatry 2008;79:840841.

6 Pearce JMS: Théodore Herpin: neglected contributions in the understanding of epilepsy. Eur Neurol 2005;54:135-139.

7 Herpin T: Des accès incomplets d'épilepsie. Paris, JB Baillière, 1867 (translation available in Schmidt, ref 10, document électronique, 1995, http://visualiseur.bnf.fr/Visualiseur?Destination $=$ Gallica \&O$=\mathrm{NUMM}$ 76917).

8 Jackson JH: A Study of Convulsions. St Andrews Medical Graduates' Association. Transactions, 1869. London, John Churchill \& Sons, 1870, pp 162-204.
9 Bright R: Reports of medical cases selected with a view of illustrating the symptoms and cure of diseases by reference to morbid anatomy, vol II: Diseases of the Brain and Nervous System, Part II. London, Longman, Rees, Orme, Brown \& Green 1831, p 538 (see also Berry and Mackenzie [14]).

10 North J: Practical Observations on the Convulsions of Infants. London, Burgess \& Hill, 1826.

11 Todd RB: Cyclopaedia of Anatomy and Physiology. London, Longman \& Roberts, Longman, Brown, Green, 1847, vol 3, p 721.

12 Todd RB: On the pathology and treatment of convulsive diseases. London Med Gaz 1849; 8:822.

13 Wilks S: Observations on the pathology of some of the diseases of the nervous system. Guys Hosp Rep 1866;12:157-244.

14 Berry D, Mackenzie C: Richard Bright, 17891858: Physician in an Age of Revolution and Reform. London, Royal Society of Medicine, 1992, pp 5-61.

15 Locock C: Address to the Royal Medical and Chirurgical Society, March 1, 1859.

16 Munk W: In Munk's Roll. Lives of the Fellows of the Royal College of Physicians of London, Published by the College, 1955, vol III, p 155.

17 Bright R: Cases of tetanus in which quinine and stimulants were administered very extensively with success. Guys Hosp Rep 1836; 1:111-118.

18 Bright R: A singular case. Lancet 1825-1826; 9:653 (cited by Berry and Mackenzie [14])
19 Bright R: Cases illustrative of the effects produced when the arteries of the brain are diseases selected chiefly with a view to diagnosis in such affections. Guys Hosp Rep 1836;1: 9-32 (cited by Berry and Mackenzie [14]).

20 Bright R: Permanent contraction of all extremities with numberless cartilaginous deposits in the arachnoid of the spinal marrow. Guys Hosp Reps 1836;1:33-35 (cited by Berry and Mackenzie [14]).

21 Bright R: Cases and observations illustrative of diagnosis when tumours are situated at the base of the brain. Guys Hosp Rep 1837;2: 279-310.

22 Cave HA: Contributions to the history of narcolepsy. Arch Neurol Psychiatry 1937;38:136139 (cited by Berry and Mackenzie [14])

23 Lee HSJ: Dates in Infectious Diseases. London, Parthenon, 2002, p 32.

24 Memoir of Dr. Bright. The Medical Times and Gazette, New Series, vol 17. London, Churchill, 1858, pp 661-662, http://books. google.com/books?id=h7JXAAAAMAAJ\& $\mathrm{pg}=\mathrm{PA} 660 \& \mathrm{lpg}=\mathrm{PA} 660 \& \mathrm{dq}=\% 22 \mathrm{emoir}+\mathrm{of}+$ Dr.+Bright.+The+Medical+Times+\%22\&so urce $=$ web\&ots $=8 \_$CRaGPBAu\&sig $=$DCU3v zZp1CCa6lbn4noAqWycvqg\&hl=en\&sa=X \&oi=book_result\&resnum $=1 \& c t=$ result.

25 Barlow GH: Obituary notice. Med Times Gaz 1858;17:632. Medical Times and Gazette of December 25, 1858 .

26 Barlow GH: Eulogium on Dr. Bright. Lancet 1843/44:i:244.

27 Bright P: Dr. Richard Bright, 1789-1858. London, The Bodley Head, 1983. 